\title{
Les nègres em pastiche wilsoniano no Festival d'Automne
}

\author{
Ana Pais
}

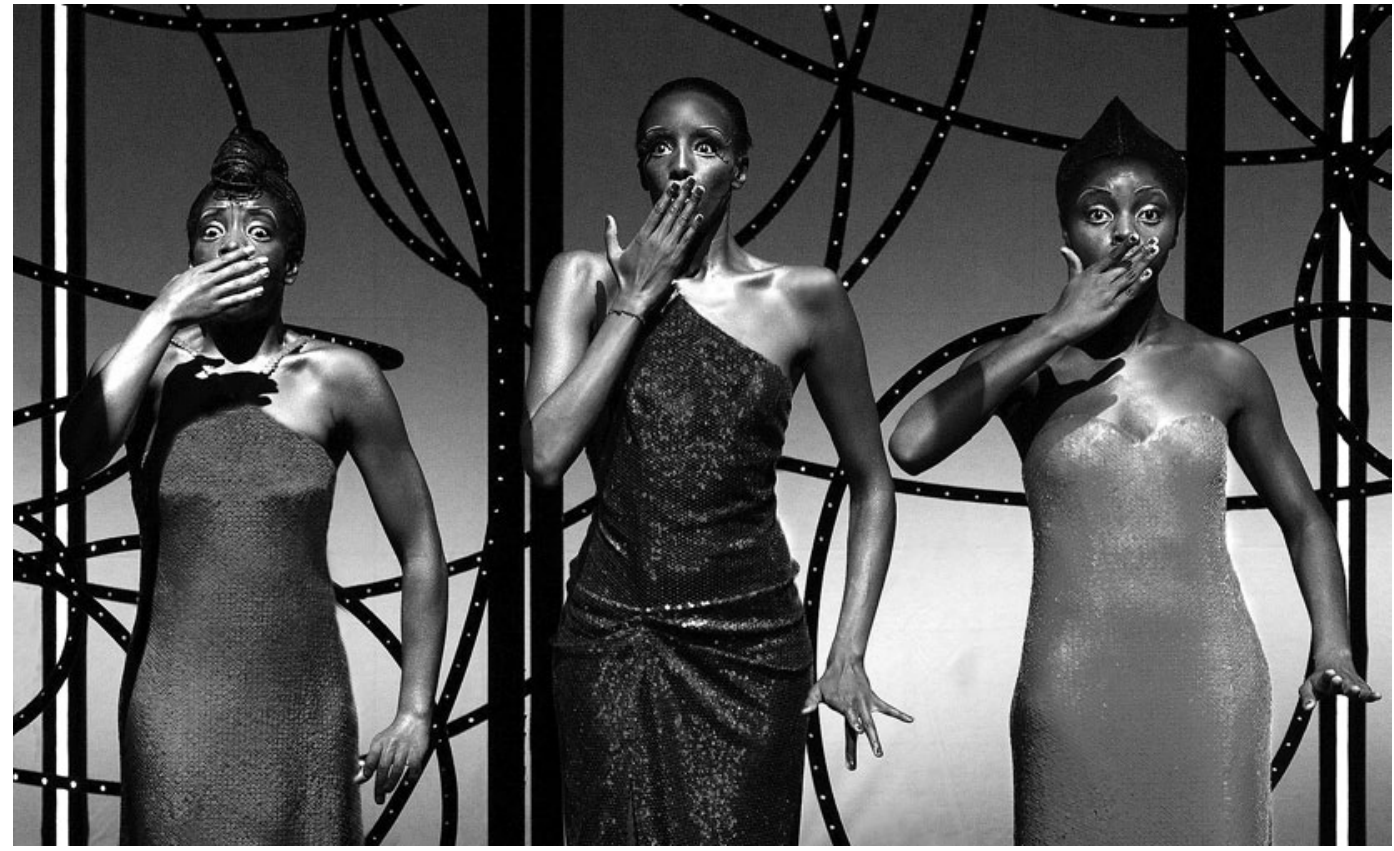

Bob Wilson seguiu a indicação cénica de Genet: reunir um elenco de actores de origem africana para a sua encenação de Les nègres, no teatro Odéon em Paris. Este foi o desafio colocado ao dramaturgo, quando o texto the foi encomendado em 1956, mais especificamente, um texto para ser representado por actores negros para uma plateia branca. Alguns anos antes, o psiquiatra Frantz Fanon havia publicado o influente volume Peau noir, masques blancs, no qual faz uma critica avassaladora ao colonialismo e às formas de racismo existentes na sociedade ocidental, no geral, e na francesa, em particular. As máscaras brancas referem-se às convenções sociais e culturais criadas pelo ocidente - pelo poder que organizou o mundo e as relações sociais e culturais com o "outro" - e impostas aos países colonizados. A proposta de Genet ecoa a denúncia desta imposição pelo disfarce teatral, em que as máscaras se tornam parte de um discurso metateatral. Qual a actualidade destas premissas em 2014, num espectáculo encomendado a Bob Wilson para o Festival d'Automne?

A encenação tem todos os ingredientes que poderiamos esperar de Bob Wilson: cenografia e iluminação grandiosas e tecnicamente sofisticadas, interpretações estilizadas e de uma fisicalidade espartilhada, o texto como o material cénico que entra em último lugar no processo (conforme relato do encenador em entrevista no dossiê de imprensa).
No prólogo inicial, ao som de tiros, os actores assomam à boca de cena e cristalizam posturas de dor, para de seguida entrarem, um a um, na porta de uma casa de Dogon. Depois disso inicia a representação do teatro dentro do teatro. Vestidos de lantejoulas num colorido exuberante, os actores, cantores e bailarinos que representam a peça dentro da peça ocupam a boca de cena. Num plano superior, a corte - actores negros vestidos e mascarados de branco - ocupa uma estrutura metálica de onde assistirá, como se de um camarote se tratasse, à representação. 0 ritmo do free jazz (Dickie Landry) associado aos neons verdes de palmeiras de metal e às linhas de luzes variadas que assinalam os diferentes planos e formas de elementos cénicos, incluindo o arco de proscénio, conferem à clownerie proposta por Genet um carácter exótico e uma tonalidade kitsch.

É neste cartão postal de uma espécie de paraiso distante e falso que o texto de Genet é proferido, sem uma (re)leitura política ou estética que sustente as opções cénicas ou sem que elas consigam mostrar a necessidade de levar à cena este texto de Genet em particular. Apesar de competentes e enérgicos, os performers não conseguem salvar o espectáculo de uma retórica pós-modernista assente na beleza vazia da imagem cénica. Mas isto não seria o problema do espectáculo, uma vez que aquela constitui a assinatura do encenador americano, convidado
Ana Pais

é Doutorada em

Estudos de Teatro pela Faculdade de Letras da Universidade de Lisboa e tem vindo a investigar o tema "a performatividade dos afectos no acontecimento teatral”. 


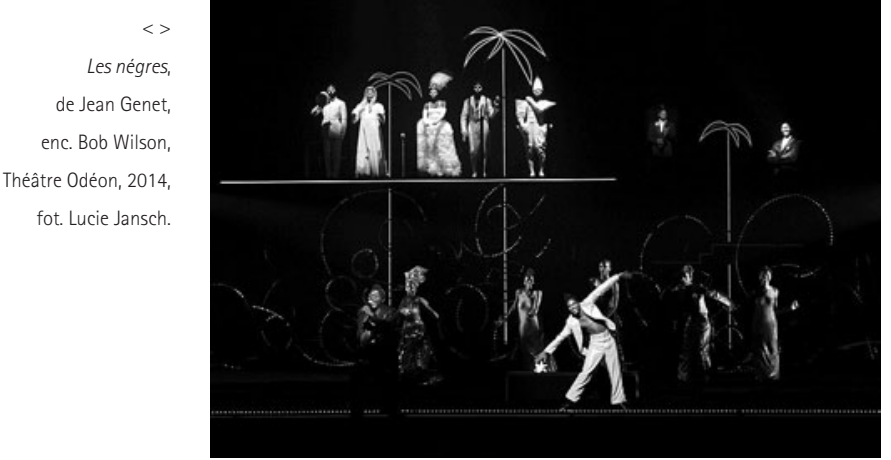

por Luc Bondy a executar esta proposta. Inquietantes são as questões que apenas à superfície de uma diplomacia multicultural parecem estar resolvidas.

No final do espectáculo, perguntei a uma senhora ao meu lado - claramente alguém que iria escrever sobre o que viu, a avaliar pelo modo desenfreado como tomava notas - se conhecia o elenco. A crítica francesa respondeu sem hesitar, num tom entre o blasé e incrédulo: "Não conheço ninguém. Tenho de ir ver ao dossiê de imprensa quem são". Intrigada, não surpreendida, procurei saber como tinha sido feito o casting. Charles Chemin, colaborador de Bob Wilson, respondeu atenciosamente. 0 processo demorou três meses. Não houve convites directos. Foram consultados encenadores e gente de teatro, mas rapidamente o boca a boca acelerou o processo e choveram currículos (centenas, segundo Chemin) e telefonemas de agentes. Realizaram-se audições, seleccionando performers, a maioria franceses ou em função da sua "personalidade" cénica e adequação aos personagens, em detrimento de uma formação específica. Como interpretar o desconhecimento total da crítica francesa face à abundância de currículos de performers negros, com percurso profissional para cumprirem a missão?

Em 2006, quando Rogério de Carvalho encenou, no Porto, este texto de Genet, colocou-se um problema de exequibilidade semelhante. Não foi possivel, apenas com os actores de origem africana residentes em Portugal, reunir um elenco para interpretar 13 personagens. Mas esta escassez faz parte de um círculo vicioso: existem poucos actores de origem africana em Portugal porque as condições materiais de acesso a uma carreira profissiona são igualmente escassas. A sua visibilidade é diminuta porque são chamados, na sua grande maioria, para papéis "temáticos", como ironicamente caracteriza o actor Ângelo Torres. 0 que desencadeia perguntas iniludiveis: Quem quer ser actor profissional num meio em que não pode crescer? Quem quer ser actor num circuito limitado que o exclui de ser actor? Quem pode ser actor quando essa profissão, para um actor de origem africana, Ihe confere um lugar de invisibilidade, amargamente correspondente a um lugar social discriminado?

Se na televisão as oportunidades são hoje diferentes, no teatro esta discriminação prevalece e actualiza o texto de Genet de forma brutal. Para além de os públicos (e penso em Lisboa) serem maioritariamente brancos, realidade já de si reveladora de uma desigualdade no acesso ao teatro, a manutenção do modelo dos actores "temáticos" perpetua uma lógica preconceituosa que discrimina profissionais pela cor da pele. Esta lógica obriga ainda a uma outra, e mais grave, perversidade: ao interpretarem
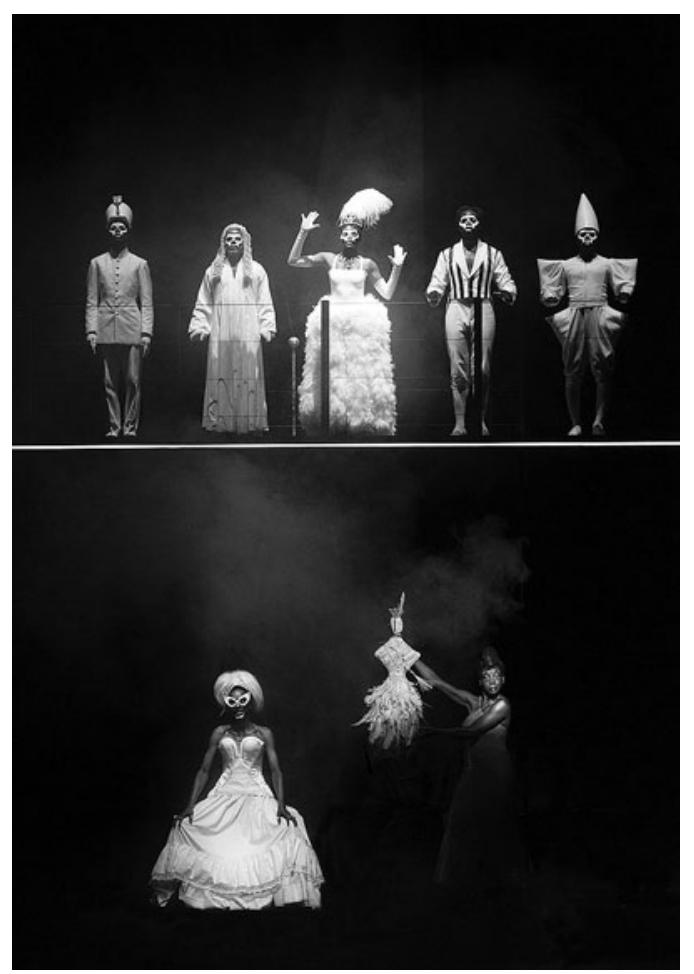

personagens de negros, os actores de origem africana perpetuam, com o seu trabalho, uma ordem de mundo criada pelo outro - no caso, o colonizador -, como denunciava Franz Fanon em 1952. Ao representarem papéis de negros nos teatros portugueses, aqueles actores estão, no mero exercicio da sua profissão, a habitar um lugar que lhes foi imposto por um regime colonizador do mundo.

Projectos como a GRIOT têm uma importância política insubstituivel na reconfiguração deste panorama e desta ordem arbitrária e injusta. Com oitenta membros aderentes ligados a diferentes artes (cinema, teatro, artes plásticas, dança, música) e residentes em Portugal, esta associação cultural tem vindo a desenvolver diversos trabalhos, com destaque para encenações de textos sobre temáticas identitárias ou autores desconhecidos do público nacional. Por exemplo, em 2013 foi levado à cena pela primeira vez em Portugal um texto do nigeriano Wole Soyinka (enc. Nuno M. Cardoso), A raça forte, assim como, mais recentemente Rogério de Carvalho encenou Confissões verdadeiras de um terrorista albino, do sul-americano Breyten Breytenbach, na última edição do programa Próximo Futuro (Fundação Calouste Gulbenkian). Também este ano, a encenação do texto de Pepetela, A geração da utopia com encenação de Guilherme Mendonça, espectáculo sobre a realidade socioeconómica dos últimos quarenta anos em Angola, obteve grande sucesso de público, fazendo supor que existe uma lacuna temática e cultural importante a suprir.

Acções como estas são fundamentais para criar as condições de visibilidade necessárias nos circuitos mediáticos e do público geral, não para constituir grupos de teatro exclusivos de actores ou artistas de origem africana - isso seria perpetuar o preconceito ao contrário -, mas para desenvolver boas práticas de colaboração que criem a sua própria ordem de mundo, em suma, que criem mundos. Se Bob Wilson viesse fazer Os negros em Portugal talvez com projectos como a GRIOT os críticos conhecessem os actores em cena. 